\title{
Research on flow in water intake of a run-of- river hydropower plant
}

\author{
Mikhail Balzannikov ${ }^{1, *}$ \\ ${ }^{1}$ Samara State Technical University, Institute of Architecture and Civil Engineering, \\ 194, Molodogvardeyskaya St., 443001, Samara, Russia
}

\begin{abstract}
The work shows the importance of flow research in parts of canal systems at hydropower plants. The authors researched a mathematical model of water intake at run-of-river hydropower plant. ANSYS software was used. The 3D model created by the authors described the upper part of the water intake extended to the approach area in front of it. The work was aimed at identifying flow parameters in the flow-narrowing zone of the water intake. The work describes the research method and presents graphical calculation results. Whirling areas were discovered in the upper part of water intake and in gate grooves. It was noted that the flow in gate grooves is spiral-shaped and runs downwards. The work highlights the danger of such flow because it increases the amount of small rubbish gravitating onto the lower part of the groove, which can cause gate hang up (blocking) when it is shut in emergency. The results are of high importance for increasing safety of intakes at run-ofriver hydropower plants.
\end{abstract}

\section{Introduction}

Hydropower plants are objects of complex construction that is why designing them involves solving safety issues. A lot of authors published their research on increasing safety of hydropower plants, for example, [1-4]. In these works, attention is drawn to researching strength properties of certain constructive elements under the influence of static and dynamic loads. As factors of such loads, they often consider weight of the construction itself, weight of equipment and its operation, automobile and railway transport [5-8].

Also, hydropower plants have a water supply canal which directs water flow to hydraulic power units and then to tailrace. Elements of the water supply canal also have quite complex construction [9-11]. They are also influenced by water flow hydraulic pressure, which should be considered while designing and justifying their geometrical properties [12-14]. Attention to hydrostatic and hydrodynamic influence on water supply canal units increased dramatically after the catastrophic accident at the SayanoShushenskaya Dam [15]. Researching physical and mathematical models of water supply canal units in order to study water flow parameters and characteristics in these units is crucial for justifying parameters of the water supply canal [16-18].

\footnotetext{
* Corresponding author: balzannikov@,samgasu.ru
} 
Water intakes at run-of-river hydropower plants have significant size and carry large amounts of water to the hydraulic power unit. Water is always supplied with significant flow narrowing (reduction in cross-section area). Most often, such narrowing in vertical plane is provided only in the upper part (Fig. 1). The constructive solution of such narrowing decreases the volume of earthwork while arranging the base plate. However, the flow narrowing at combined hydropower plants happens mostly in the lower part. (Fig. 2). The reason for such construction solution is that the entrance of bottom water collector is located lower than the intake of water supplied to the turbine chamber.

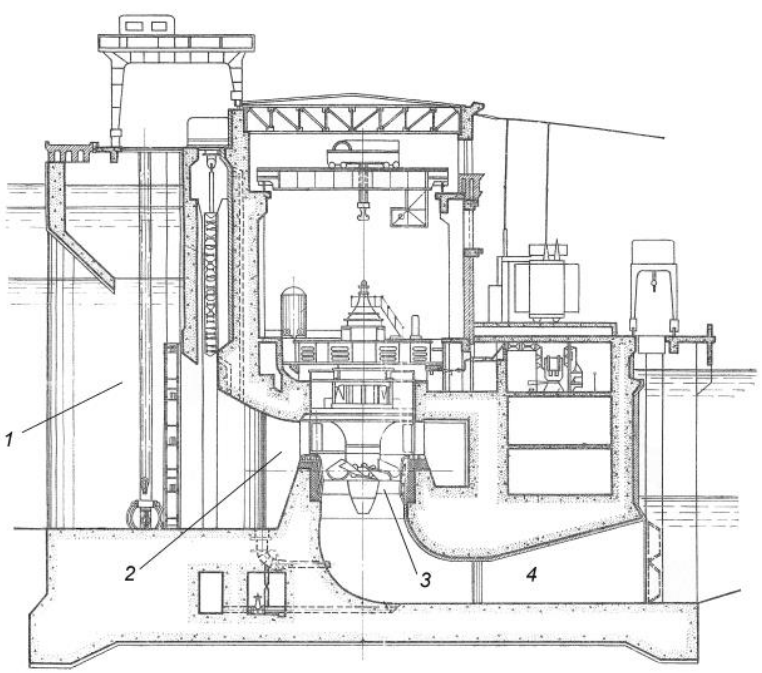

Fig. 1. Water supply canal at run-of-river hydropower plant [19]: 1 - water intake, 2 - turbine chamber, 3 - runner chamber, 4 - draft tube.

Additional constructive elements like gate grooves, curtain and divider walls are put exactly in the area of flow narrowing in the water intake. These elements significantly influence the flow character and the loss of pressure. If the sizes of constructive elements have been chosen incorrectly, this can lead to unfavourable hydraulic conditions of the flow [20].

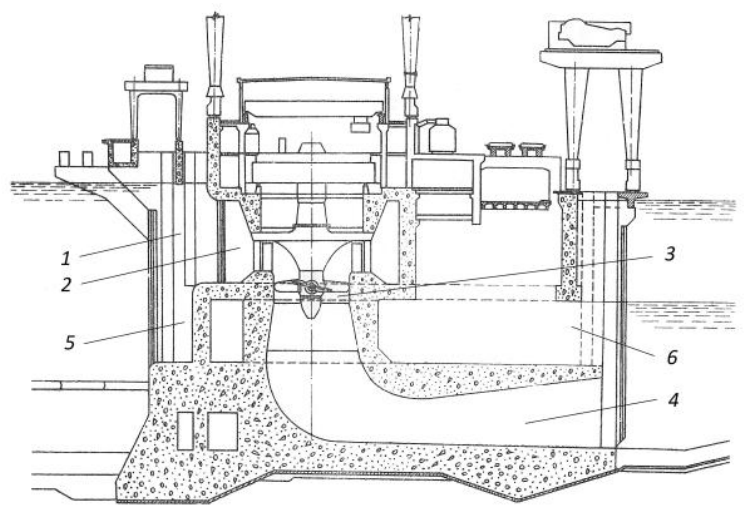

Fig. 2. Water supply canal at run-of-river hydropower plant [19]: 1 - water intake, 2 - turbine chamber, 3 - runner chamber, 4 - draft tube, 5 - tailwater entrance, 6 - tailwater exit. 
The work was aimed at identifying flow parameters in the flow-narrowing zone of the water intake at the run-of-river hydropower plant and studying the influence of constructive elements on flow character and properties.

\section{Materials and Methods}

Research was done using ANSYS software with CFX solver [21]. In order to reach the research objective, a 3D model of water intake entrance was used, extended to the approach area in front of the water intake (Fig. 3). The modelling area was divided into multiple tetrahedron-shaped elements whose size was set by the programme depending on the surface curvature and proximity to other flow-limiting surfaces. In addition, a zone of boundary layer was separated in the net, which is important for getting a broad picture of water flow in gate grooves. The modelling net included about 390000 elements.

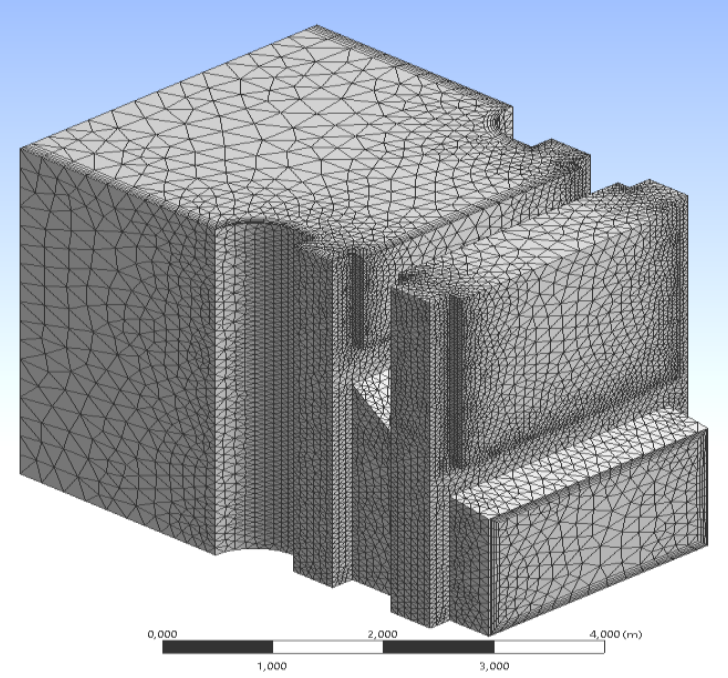

Fig. 3. 3D model of water intake with final elements net.

Gravity was taken into consideration and k- $\varepsilon$ turbulence model was chosen while performing the task in the modelling flow. The turbulence model influences the correctness, but in the given situation, these effects are of minor importance as most of open flows work in quadratic zone of resistance. Density and dynamic viscosity were set for the flow. After initializing the definition area, the following boundary conditions were set:

- Inlet water: mass flow $10000 \mathrm{~kg} / \mathrm{s}$;

- Outlet water: mass flow $10000 \mathrm{~kg} / \mathrm{s}$;

- $\quad$ Opening: pressure ratio 0 ;

- Other walls, rate of flux 0 (according to Boundary layer theory).

When setting the boundary conditions, the following admission was introduced: open water surface is not deformed in the contact zone of water entrance and intake at hydropower plant. In order to reach the stated objective, the maximum iteration number of 500 was set, but the solver could stop calculation pattern at error value $10^{-4}$. To reach this error value, 200 iterations were enough, which proves good solution convergence. The convergent graphs are shown in Fig. 4. 


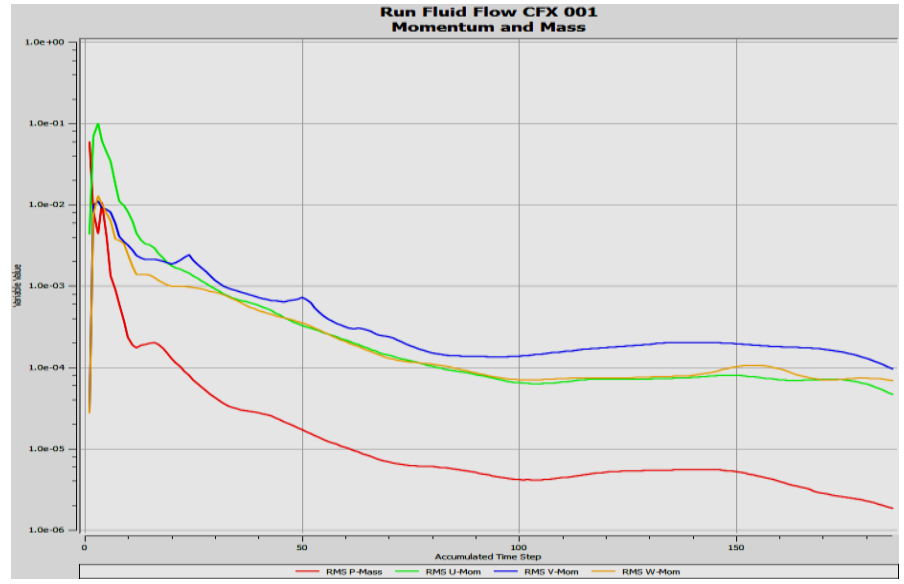

Fig. 4. Solution convergence graphs.

\section{Results}

The above mentioned methodology was used to calculate flow parameters in water intake with narrowing only in the upper part of the water supply canal at hydropower plant. Results of such calculation were visualized for presentation and further analysis.

Flow velocity parameters (direction and value) in specific vertical section are presented in Fig. 5. The received data shows that flow velocity increases when water supply canal cross-section area decreases in such a way that the maximum values are indicated in the upper part. In addition, a constant whirling zone and upward water flow appear between divider and intake walls.

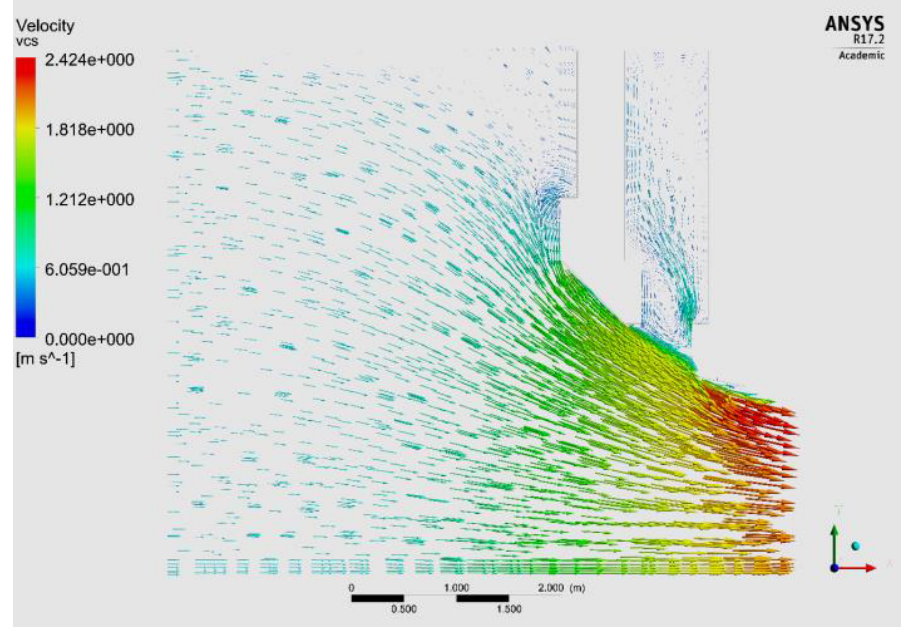

Fig. 5. Flow velocity in vertical plane.

Fig. 6 gives data of flow velocity in horizontal plane of water intake. The area where the water supply canal narrows and the flow velocity increases also has certain construction elements which influence the water flow. They are gate grooves.

Results of flow research in these grooves are presented in detail in Fig. 7 and 8 . Fig. 7 shows distinctly that constant whirling areas are formed in the grooves. In addition, 
downward flow is detected in vertical section going through gate grooves (Fig. 8). This proves that the flow in gate grooves is spiral-shaped, curled and directed downwards.

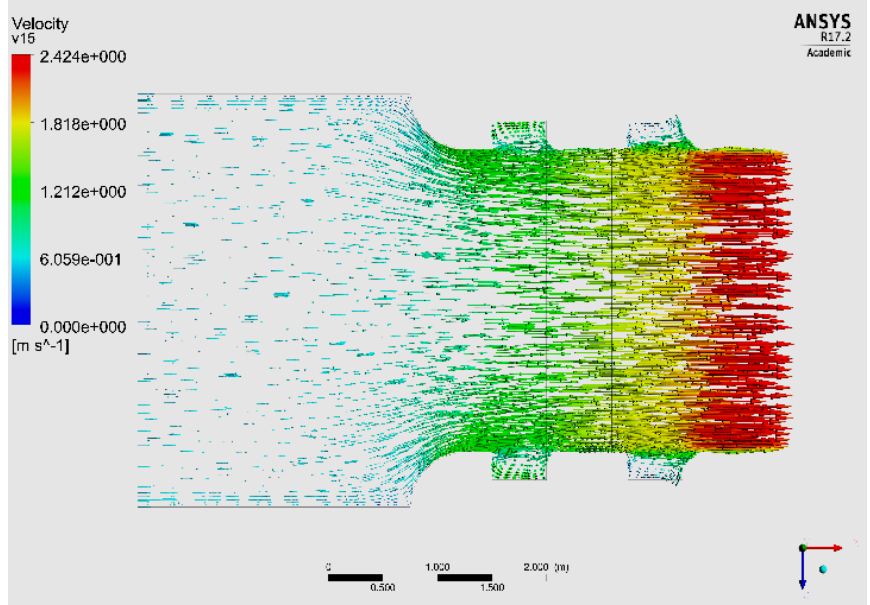

Fig. 6. Flow velocity parameters in horizontal plane.

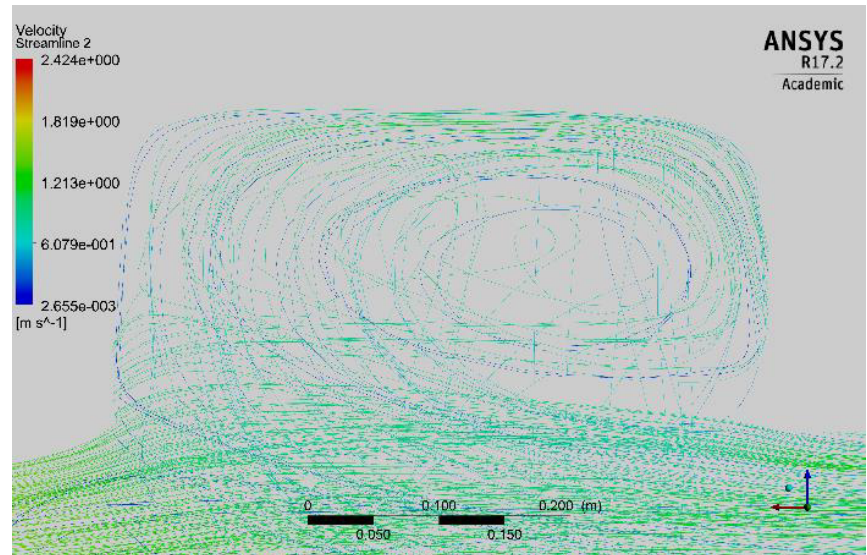

Fig. 7. Flow velocity parameters in water intake grove in horizontal plane.

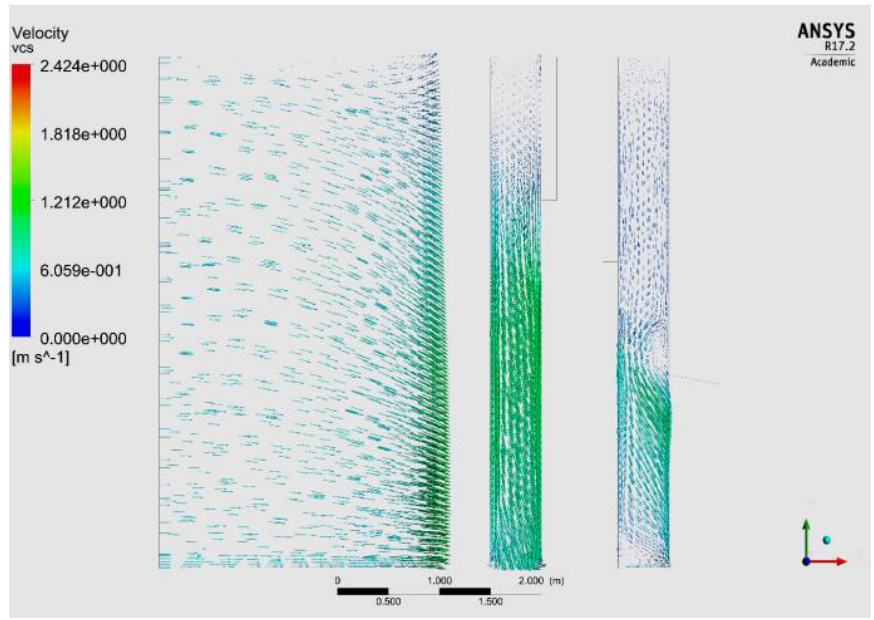

Fig. 8. Flow velocity parameters in water intake grove in vertical plane. 


\section{Discussion}

Research of the flow in water intake discovered constant whirling areas in the zone of flow narrowing in cross section area at run-of-river water plant. In addition, upward and downward flows appear in separate areas. Whirling zones cause pressure loss and weaken the hydropower plant effectiveness. Besides, water spirals breakdowns can happen in whirling areas, which will inevitably increase the dynamic load on the intake and decrease safety of the whole construction.

In our opinion, the biggest danger is downward spiral-shaped flow in the intake gate grooves. The flow carries small rubbish, which gravitates onto the lower parts of the groove. Therefore, large amounts of such rubbish can cause hang up (blocking) of gate when it is shut in emergency. This is inadmissible under high safety conditions of a hydropower plant.

The achieved results are of high importance for correctly choosing the form and the geometrical parameters of the intake constructive elements. Besides, the results highlight the necessity of regular inspections of the lower part of the grooves in order to find and remove any gravitated rubbish. Such actions will provide high safety at hydropower plant.

\section{Conclusions}

The main conclusions of the research can be formulated as follows:

1. Research on flow parameters in complex constructive elements of water supply canal are of high importance for correctly choosing the form and the geometrical parameters of these elements. Justified forms and sizes of water intake elements allow to decrease the dynamic load on the water intake and, as a result, to increase the water supply canal safety.

2. Research showed that the flow in gate grooves of the water intake at run-of-river hydropower plant that is characteristic of narrowing the flow section only at the upper part is spiral-shaped and runs downwards. Such flow direction is dangerous as it can carry small rubbish, which gravitates onto the lower parts of the groove. Large amounts of such rubbish can cause hang up (blocking) of gate when it is shut in emergency.

3. In order to maintain high safety of the hydropower plant and its water intake it is recommended to perform regular inspections of the lower part of the grooves in order to find and remove any gravitated rubbish.

\section{References}

1. S.V. Evdokimov, Urban Construction and Architcture 2(5), 68-74 (2012)

2. Yu.S. Vasiljev, L.I. Kubyshkin, Hydraulic Engineering 7, 2-8 (2014)

3. M. Balzannikov, V. Alpatov, I. Kholopov, A. Saharov, A. Lukin, MATEC Web of Conferences 73, 01012 (2016)

4. A.A. Romanov, Hydropower constructions maintenance (Agni Publishing House, Samara, 2010)

5. A.A. Romanov, S.V. Evdokimov, V.A. Seliverstov, Industrial and Civil Engineering 6, 44-48 (2015)

6. F. Svitala, S.V. Evdokimov, Yu.M. Galitskova, Industrial and Civil Engineering 12, 8790 (2014)

7. F. Svitala, Yu.M. Galitskova, Scientific Srvey 10, 450-456 (2014)

8. M.I. Balzannikov, Procedia Engineering 111, 65-71 (2015) 
9. S.A. Pijavskij, S.V. Evdokimov, Bulletin of higher education establishments. Construction 6, 36-43 (2012)

10. V.P. Popov, A.A. Mihasek, V.A. Seliverstov, Vestnik KGUSTA 1, 73-79 (2014)

11. L.G. Kozinets, Alternative Energetics and Ecology 13-14, 26-30 (2015)

12. L.G. Kozinets, L.P. Potehin, Engineering Construction Journal 6, 29-35 (2012)

13. Y.E. Senitsky, M.I. Balzannikov, A.A. Mikhasek, Urban Construction and Architecture V.7, 1, 64-69 (2017)

14. M.I. Bal'zannikov, V.A. Seliverstov, Power Technology and Engineering 49, 22-26 (2015)

15. V.I. Fortov, M.P. Fiodorov, V.V. Yelistratov, Vestnik of Russian Academy of Sciences 7, 579-586 (2011)

16. I.A. Bahtina, B.M. Ivanov, S.V. Iljinih, P.V. Stepanova, E.S. Yelizarov, Polzunovsky Vestnik 4-2, 12-19 (2013)

17. B.U. Urishev, M.M. Muhammadiev, F. Nosirov, S.R. Zhuraev. Urban Construction and Architecture 4, 49-53 (2013)

18. M. Balzannikov, S. Piyavsky, A. Kurmanayev, MATEC Web of Conferences 86, 02006 (2016)

19. Yu.S. Vasiljev, V.V. Elistratov, Hydroelectric power plants (St. Petersburg Polytechnic University, Saint Petersburg, 2011)

20. Yu.S. Vasiljev, V.V. Elistratov, L.N. Kubishkin, Hydraulic Engineering 5, 11-18 (2007)

21. V.A. Seliverstov, Scientific technical bulletin of St. Petersurgh Polytechnic University 4-2, 149-153 (2009) 